\title{
EXPERIMENTAL EVALUATION OF A 3 kW ABSORPTION CHILLER PROTOTYPE
}

\author{
T. O. Ahmadu* \\ Department of MeChanical Engineering, Ahmadu Bello University, Zaria, KadunA State, NIGERIA \\ E-mail address: talibahmadu@gmail.com
}

\begin{abstract}
Thermally driven absorption chillers have the advantage of being powered by renewable or waste heat as well as using environmentally friendly refrigerants. However, micro scale capacities suitable for residential and office applications are still lacking. This study presents the experimental evaluation of a developed $3 \mathrm{~kW}$ capacity, single effect, hot water fired absorption chiller prototype. The chiller operates on the lithium bromide - water pair. To enhance wettability in the absorber, a double - tube configuration was employed to aid the falling film mode. Experimental test on the chiller showed the chilled water outlet temperatures from the evaporator ranged between 16.3 to $20.5^{\circ} \mathrm{C}$. The chiller response time to cooling was about 15 minutes from the commencement of evaporation process at the evaporator. The chiller pressures stayed below 9 kPa throughout the experiment. Maximum cooling power of $2.01 \mathrm{~kW}$ was recorded, representing $67 \%$ of nominal cooling capacity. Maximum coefficient of performance (COP) of 0.47 was recorded, while an average COP of 0.43 was recorded.
\end{abstract}

Keywords: absorption chiller, double - tube, experiment, cooling power, COP

\section{INTRODUCTION}

Energy is an essential need of human beings all over the world. The global demand for energy has increased over the last few decades, with fossil fuels being the prominent source for generating utilizable forms of energy. This makes fossil fuels the major contributor to global warming and greenhouse effect on the ozone [1]. Increasing occupants indoor comfort demands has led to growth in thermal cooling loads notably during peak periods [2]. Usually, vapour compression based cycles are employed in air conditioning of building space. However, these units are usually electrically powered, consuming large amounts of high quality energy, which significantly increases the fossil fuel consumption [3]. In Nigeria, space cooling is achieved mainly by the use of mechanical vapour compression systems. However, unreliability of grid electricity supply as well as rise in cost of energy leads to huge economic loss [4]. In addition to this, electrically powered vapour compression chillers operate with synthetic refrigerants such as hydro - chlorofluorocarbons (HCFCs), which when released into the atmosphere constitute high Ozone Depleting Potential (ODP) [3]. The need to safeguard the environment from the effect of fossil fuel use as well as from the effect of harmful refrigerants has led to research interest in thermally driven absorption air conditioning systems which use environmentally friendly refrigerants [2]. The most commonly used absorption chiller is that which operates on the lithium bromide/ water pair [5]. The heat source temperature is usually within $70-$ $100^{\circ} \mathrm{C}$, they therefore have the advantage of being powered by renewable or waste heat. Although great developments have been achieved in absorption air conditioning systems, with absorption chillers available in commercial stage in small capacity (10 to $40 \mathrm{~kW}$ ), medium capacity (50 to $250 \mathrm{~kW}$ ) and large scale (up to tens of MW), the micro scale ( 3 to $10 \mathrm{~kW}$ ) which is most suitable for residential and office applications is substantially unexplored [6]. Major drawbacks in micro scale capacity applications is in the high fabrication 
cost as well as in the low Coefficient of Performance (COP) of the absorption chillers as compared to much higher COP obtained in electrically powered compression chillers of similar capacity [7]. The major components in absorption chillers are the generator, condenser, evaporator and absorber, which are all heat exchangers. The absorber can be said to be the most important component of absorption machines as in general, its performance impacts directly on the size and energy supply of all absorption devices. The absorber is therefore the ultimate component in optimizing the COP of the device [8]. Falling film absorbers which are generally employed in absorption chillers have a wettability problem which diminishes absorption process [8]. A number of researchers have developed micro scale capacity absorption chiller prototypes, with improvements in absorber design aimed at improving the COP. A prototype micro scale absorption chiller of $5 \mathrm{~kW}$ nominal cooling capacity was developed by [6]. All the heat exchangers had a spiral configuration. Experiments on the chiller gave an effective cooling capacity of $3.25 \mathrm{~kW}$, corresponding to a COP of 0.358. A single effect absorption chiller prototype of $5 \mathrm{~kW}$ cooling capacity has been constructed. The chiller operates with the ammonia/ water pair. Plate heat exchangers were employed in the generator, evaporator and absorber, with the absorber having finned outer surface. Experimental tests gave maximum COP of 0.43 [9]. An absorption chiller of $7 \mathrm{~kW}$ capacity working on the lithium bromide water pair was constructed. A minimum chilled water temperature of $13.8^{\circ} \mathrm{C}$ was achieved when the average supply hot water temperature was $84.4^{\circ} \mathrm{C}$. Average COP of 0.52 was recorded [10]. An air cooled two stage absorption chiller prototype of $2 \mathrm{~kW}$ capacity working on the ammonia/ water pair has been developed. The absorber design employed threaded tubes for improved tube wetting. Experimental results indicated a COP in the range of 0.18 to 0.25 when driven by hot water of $85^{\circ} \mathrm{C}$ [7]. Design and construction of a double effect $7 \mathrm{~kW}$ capacity absorption chiller prototype was carried out. The chiller was air cooled and employed a flat sheet adiabatic absorber for enhanced tube wetting. The chiller was able to chill water up to 7 to $18{ }^{\circ} \mathrm{C}$ and attained a mean daily COP of about 1.05 [11]. The present study presents the experimental evaluation of a developed single effect absorption chiller prototype of $3 \mathrm{~kW}$ capacity, working on the lithium bromide/ water pair. To enhance tube wetting in the absorber, a "double tube" configuration was employed in the absorber design.

\section{BASIC CYCLE OF SINGLE EFFECT ABSORPTION CHILLER}

The system description presented here is done using the state points as seen in Figure 1. Hot water, heated by an external heat source flows into the chiller $(11 / 12)$ to the generator, where vaporization of refrigerant takes place. The vapour streams to the condenser (1) where cooling water (13/14) aids condensation under condenser temperature and pressure. The resulting strong solution from generator flows to the absorber through the Solution Heat Exchanger (SHX) and valve [8-10]. The condensate (liquid refrigerant) flows through the valve to the evaporator $(2,3)$, where it takes away heat from the chilling water (15/16) and evaporates again under evaporator temperature and pressure. The refrigerant vapour streams to the absorber (4) where it is absorbed by the strong solution. The resulting weak solution, is then pumped via the solution pump, through the solution heat exchanger, back to the generator [5-7] and the cycle repeats again.

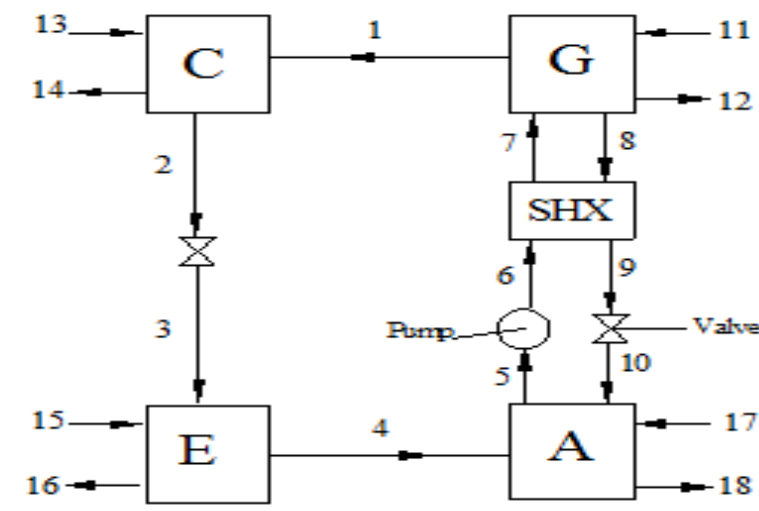

Figure 1: Schematic of a single effect absorption cooling cycle

\section{METHODOLOGY}

This section describes the absorption chiller prototype as well as outlines the experimental test carried out on the chiller.

\subsection{Absorption Chiller Prototype Description}

The $3 \mathrm{~kW}$ nominal cooling capacity absorption chiller prototype was designed and constructed using locally available materials and expertise. The chiller consists of the following components: Generator (G), Condenser (C), Absorber (A), Evaporator (E), Solution Heat Exchanger (SHX), Hot water pump (HWP), Chilled water pump (CWP), Solution circulation pump 
(SCP), Refrigerant circulation pump (RCP), Throttle valve (TV), Flow valves (FV). The chiller is hot water fired. Hot water, heated by an external heating source (solar or gas) is pumped by the hot water pump (HWP) to the generator $(\mathrm{G})$. The generator is a horizontal shell and tube heat exchanger designed to operate in pool boiling mode. In the generator, weak solution of lithium bromide (low in lithium bromide concentration) is desorbed. The refrigerant (water) vapourizes and flows to the condenser (C), where it condenses to liquid refrigerant. The resulting strong solution of lithium bromide (high in lithium bromide concentration), which is at generator pressure, flows by gravity through the solution heat exchanger (SHX), which was designed as a concentric tube heat exchanger. It then flows through a throttle valve (TV) where it is reduced to absorber pressure, and eventually flows to the absorber (A). The condenser (C) is a water cooled horizontal shell and tube heat exchanger, sloped at an angle to allow easy drainage of condensate refrigerant. Cooling water is supplied to the condenser from an external cooling tower. The condensed refrigerant from the condenser, which is at condenser pressure, flows by gravity through a throttle valve (TV), where it is reduced to evaporator pressure, and eventually flows down to the evaporator (E). The evaporator is a vertical shell and tube heat exchanger which was designed to operate in falling film mode. At the evaporator, water is circulated through the tubes by the chilling water pump (CWP), while the refrigerant circulating pump (RCP) circulates

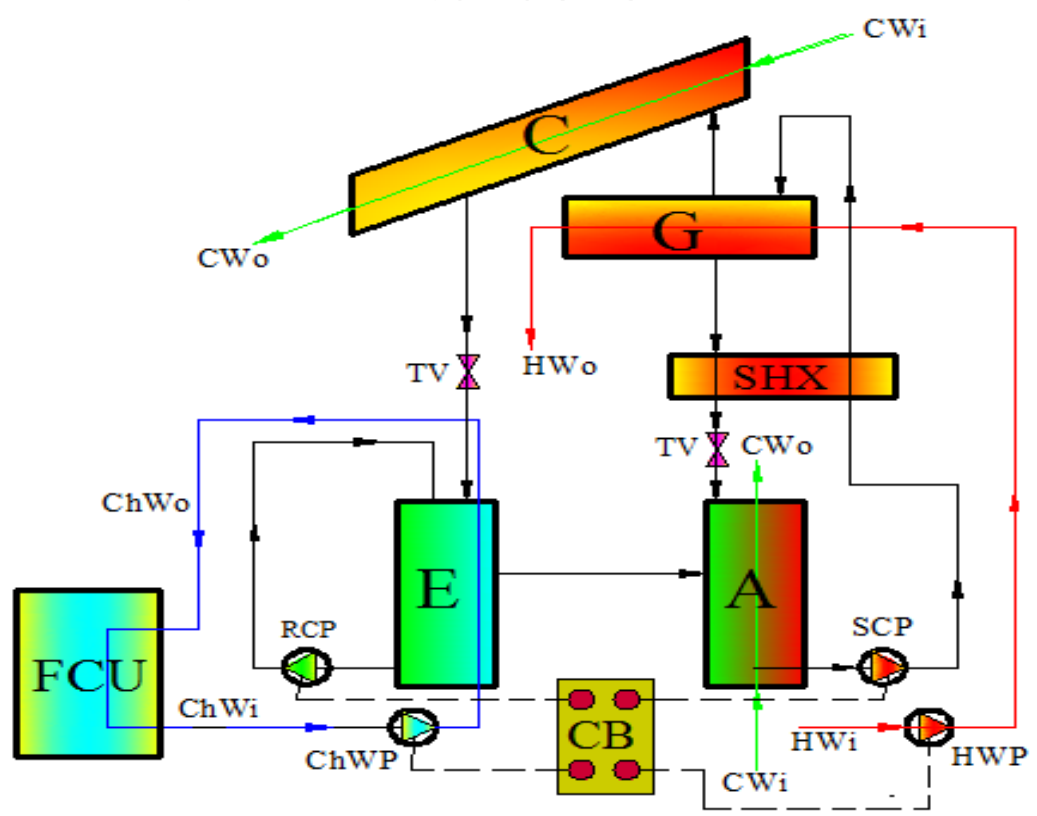

Figure 2: Schematic of the absorption chiller prototype liquid refrigerant over the absorber tubes. Evaporation of liquid refrigerant which flows over the tubes takes place at evaporator pressure. The resulting chilled water is pumped to the fan coil unit (FCU), while the refrigerant vapour flows to the absorber $(A)$. The absorber is a vertical shell and tube heat exchanger in which a "double tube" falling film configuration was designed. The absorber is water cooled by an external cooling tower. At the absorber, the strong solution of lithium bromide absorbs refrigerant vapour and results into a weak solution of lithium bromide, from where it is pumped by the solution pump (SP) through the solution heat exchanger back to the generator and the cycle repeats again. Figure 2 shows the schematic of the absorption chiller prototype, while figures 3 to 5 are pictures of the absorption chiller.

\subsection{The Double Tube Absorber Configuration}

To enhance tube wetting process in the absorber, a "double tube" absorber design was done to aid the falling film mode. Here, an outer tube directs falling film of lithium bromide solution (strong solution) onto the inner tube. Cooling water flows in the inner tubes, strong solution of lithium bromide falling film is conveyed by the outer tubes over the inner tubes in counter flow mode. The outer tubes are much shorter towards the sump where the solution absorbs refrigerant vapour. A cross section of the double tube configuration in the absorber is shown in Figure 6.

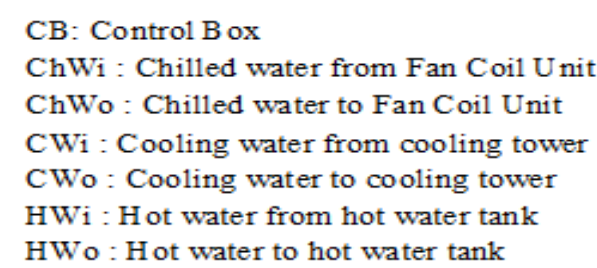

CB: Control B ox CWi : Cooling water from cooling tower HWi : Hot water from hot water tank HWo: $\mathrm{H}$ ot water to hot water tank 


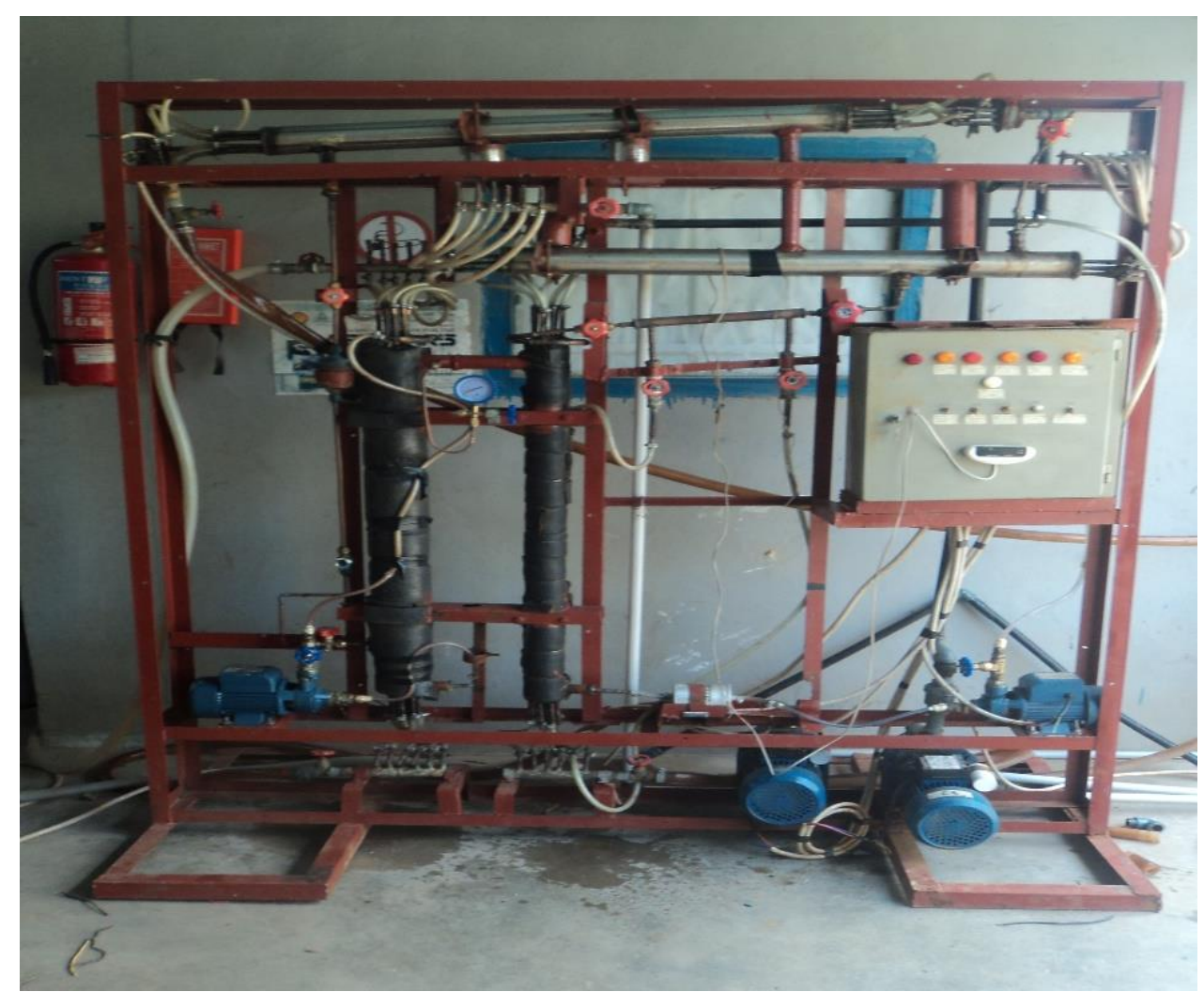

Figure 3: The $3 \mathrm{~kW}$ absorption chiller prototype

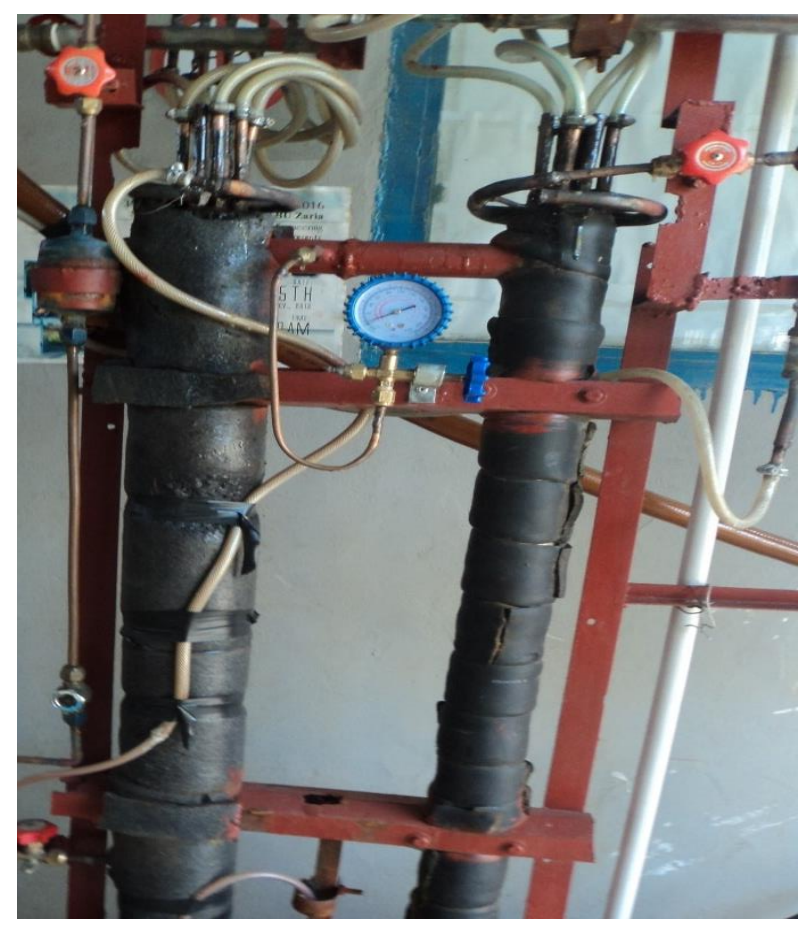

Figure 4: Close up view of Absorber and Evaporator

\subsection{Chiller Pressure and Lithium Bromide Solution Concentration}

The absorption chiller operates at pressures below atmospheric pressure (vacuum pressure). The chiller was therefore vacuumed and kept air tight. If the

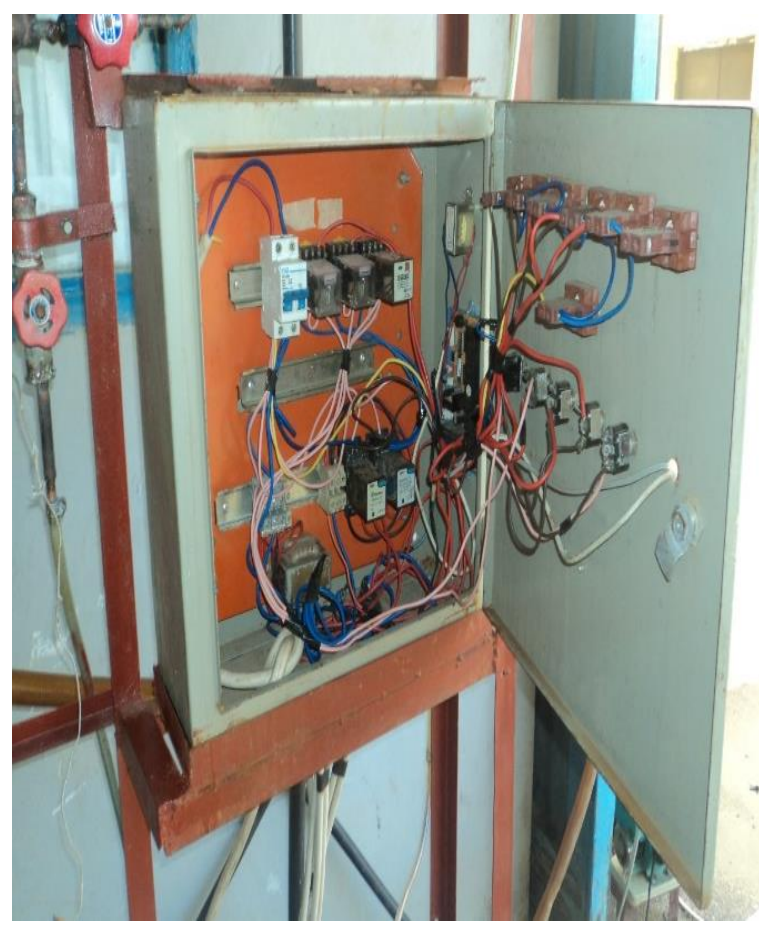

Figure 5: The Control Box

system loses vacuum, pressures increase up to atmospheric pressure. This weakens evaporation process which reduces performance. A pressure guage was mounted on the chiller to monitor chiller pressure. When the chiller pressure increased above $10 \mathrm{kPa}$, 
system was vacuumed using a vacuum pump. Lithium bromide is a salt with a crystalline structure, when it gets below its minimum temperature, the salt leaves and crystallizes [10]. Crystallization occurs when solution concentration is too high or solution temperature is too low. The most prone point to crystallization is at the point of strong solution entry to the absorber. Here, concentration is highest and temperature is low [10]. A design entry temperature of strong solution to the absorber of $40^{\circ} \mathrm{C}$ was used. From figure 7 , solution concentration of $58 \%$ at $40^{\circ} \mathrm{C}$ produces a vapour pressure of $0.7 \mathrm{kPa}$, which is sufficiently low absorber pressure and well above the crystallization curve, thus the crystallization range is avoided. For this reason strong solution concentration of $58 \%$ was used.

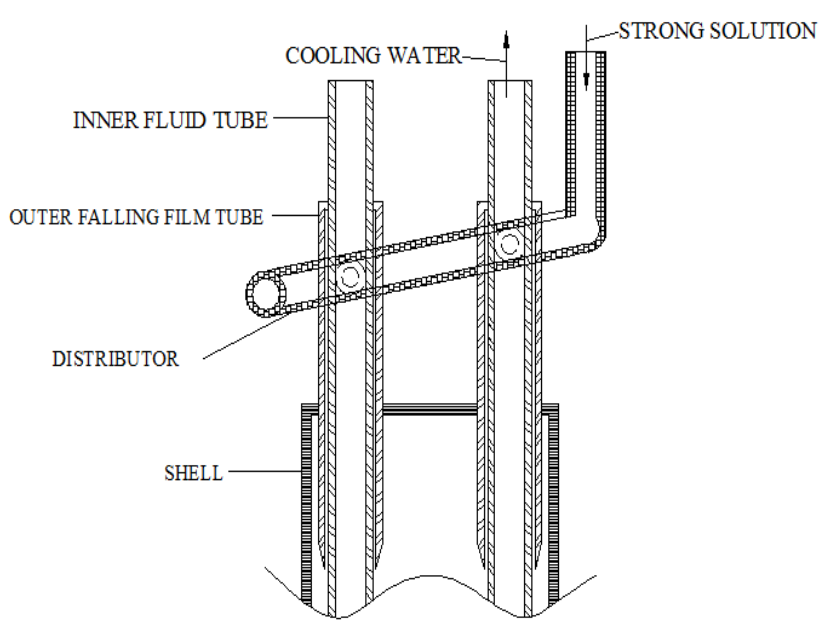

Figure 6: Cross section of absorber configuration

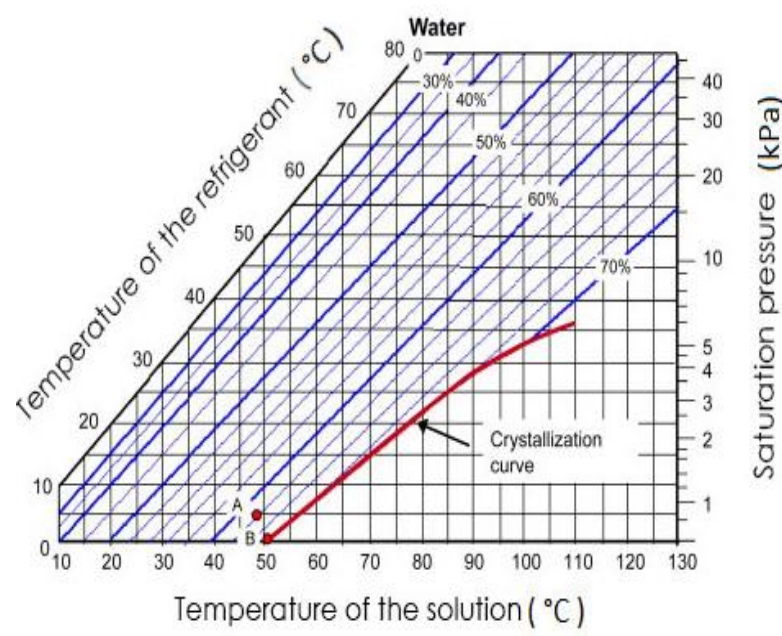

Figure 7: Chemical property chart of lithium- bromide - water solution [12]

\subsection{Experimental Procedure}

Experimental tests were conducted on the absorption chiller prototype. The experiment reported in this paper was conducted on the $19^{\text {th }}$ of April, 2017 at the heat engine laboratory of the department of mechanical engineering, Ahmadu Bello University, Zaria, Nigeria. A liquefied petroleum gas burner was used to supply the thermal energy to generate the hot water used to fire the absorption chiller. The hot water was heated to a set temperature of $95^{\circ} \mathrm{C}$ before it was pumped to the generator. The hot water, chilled water and cooling water pumps were set to start up at the same time on commencement of the experiment, while the solution circulating pump and refrigerant circulating pump were set to start up 15 minutes later. This was to allow for desorption of aqueous lithium bromide solution as well as condensation of refrigerant at the generator and condenser respectively before circulation. Cooling is expected to commence at the start-up of the refrigerant circulating pump. Heat was rejected from the absorption chiller to the cooling water stream at the condenser and absorber. The cooling water was cooled by an external cooling tower. Thermocouple wires were connected at inlet and outlet to the generator, absorber, SHX, condenser and evaporator, to measure hot water temperature, cooling water temperature, solution temperature, and chilled water temperature. Pressure gauge was connected to measure generator - condenser pressure and absorber - evaporator pressure. A flow meter was used to measure volume flow rates of the hot and chilled water streams as well as cooling water stream. The process was run for 6 hours while measurements were taken every 15 minutes.

\subsection{Measuring Instruments}

The following measuring instruments were used:

i. Digital thermocouple thermometer: model no.: T407291, measuring range: $-50-1300^{\circ} \mathrm{C}$, accuracy: $0.1 \%+1^{\circ} \mathrm{C}$

ii. Bourdon tube pressure guage: model no.: ASME B40 - 100 measuring range: -1 bar-24bar, accuracy class: $2 \%$ in the first $75 \%$ of scale, $5 \%$ in the last $25 \%$ of scale.

iii. Digital flow meter: model no.: PT - 11, measuring range: $0.1 \mathrm{~L} / \mathrm{hr}-100 \mathrm{~L} / \mathrm{hr}$, accuracy: $\pm 4 \%$

\subsection{Evaluation of Chiller Performance}

The performance of the chiller was evaluated by its cooling capacity $\left(Q_{e}\right)$, the generator heat input $\left(Q_{g}\right)$ heat rejected to the cooling water stream $\left(Q_{c}\right)$ and the Coefficient of Performance (COP). These performance indices were calculated as below:

i. The cooling capacity was calculated as: 


$$
Q_{e}=\dot{m}_{c h w} C_{p, c h w}\left(T_{c h w, i}-T_{c h w, o}\right)
$$

ii. The generator heat input was calculated as:

$$
Q_{g}=\dot{m}_{h w} C_{p, h w}\left(T_{h w, i}-T_{h w, o}\right)
$$

iii. The heat rejected to the cooling water stream was calculated as:

$$
Q_{c}=\dot{m}_{c w} C_{p, c w}\left(T_{c w, o}-T_{c w, i}\right)
$$

iv. The COP was calculated as:

$$
\mathrm{COP}=\frac{Q_{e}}{Q_{g}}
$$

where: $\dot{m}_{c h w}$ is the mass flow rate of chilled water stream; $\dot{m}_{h w}$ is the mass flow rate of hot water stream; $\dot{m}_{c w}$ is the mass flow rate of cooling water stream; $C_{p, c h w}$ is the specific heat capacity of the chilled water; $C_{p, h w}$ is the specific heat capacity of the hot water; $C_{p, c w}$ is the specific heat capacity of the cooling water

$T_{c h w, i}$ and $T_{c h w, o}$ are the inlet and outlet chilled water stream temperatures to the chiller respectively

$T_{h w, i}$ and $T_{h w, o}$ are the inlet and outlet hot water stream temperatures to the chiller respectively

$T_{c w, i}$ and $T_{c w, o}$ are the inlet and outlet cooling water stream temperatures to the chiller respectively

\section{RESULTS AND DISCUSSIONS}

Figure 8 shows the temperature profiles of the three water loops: the hot water, cooling water and chilled water at inlet and outlet points of the chiller. As seen from the figure, there is a wide temperature difference of about $25^{\circ} \mathrm{C}$ between the inlet and outlet hot water temperatures at 9:00 hr which is the start of the experiment. This was due to the system inertia that needs to be overcome at the start of the experiment. The cooling water stream at the start of the experiment is seen to be at $30^{\circ} \mathrm{C}$. However at 9:15 hr the cooling water enters the chiller at a temperature of $30^{\circ} \mathrm{C}$ and exits at a temperature of $43^{\circ} \mathrm{C}$, representing a temperature difference of $13^{\circ} \mathrm{C}$. This is because, at this time, desorption of the aqueous lithium bromide solution at the generator had commenced, causing the saturated refrigerant vapour to flow to the condenser, where the heat of condensation is rejected to the cooling water stream. Steady state was however attained at about $9.30 \mathrm{hr}$, representing 30 minutes from the commencement of heating at the generator. Also, chilled water temperatures are seen to drop from $29^{\circ} \mathrm{C}$ at 9:00 hr to $25^{\circ} \mathrm{C}$ at 9:30 hr., from where the chilled water outlet temperature begins to get significantly lower than the chilled water inlet temperature. This indicates chilling by the absorption chiller. During the steady state period, the average temperature difference between the inlet and outlet of the hot water, cooling water and chilled water loops varied between 4.5 to $6.0^{\circ} \mathrm{C}, 3$ to $6^{\circ} \mathrm{C}$ and 1.5 to $3.5^{\circ} \mathrm{C}$ respectively. Also, during the steady state period the average recorded hot water inlet temperature was $87.6^{\circ} \mathrm{C}$, while the recorded chilled water outlet temperatures ranged between 16.3 to $20.5^{\circ} \mathrm{C}$. The minimum chilled water outlet temperature of $16.3^{\circ} \mathrm{C}$ was achieved when the supply hot water temperature was $89^{\circ} \mathrm{C}$. This indicates that the absorption chiller was able to achieve the desired chilling.

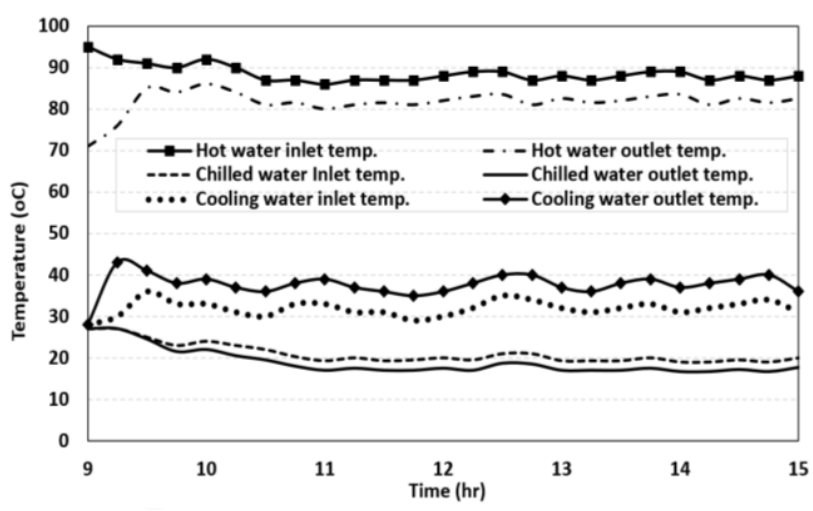

Figure 8: Variation of hot water and chilled water temperatures with time

Figure 9 shows the temperature profiles of the strong and weak lithium bromide solutions while flowing through the SHX. As mentioned earlier, the solution circulation pump was set on 15 minutes after the hot water, cooling water and chilled water pumps were set on, representing 9:15 hr as seen in the figure. The four fluid streams are seen to rise in temperature from 9:15 hr and attain steady state at 9:45 hr. During steady state, the strong solution temperature at outlet from the generator ranged between 68 to $72^{\circ} \mathrm{C}$. At inlet to the absorber, after passing through the SHX, the strong solution temperature can be seen to have dropped and ranged between 58 to $63^{\circ} \mathrm{C}$. This indicates cooling of the strong solution at the SHX. Also, the weak solution temperature at outlet from the absorber is seen to range between 40 to $43^{\circ} \mathrm{C}$. However, at inlet to the generator after passing through the SHX, the weak solution temperature is seen to rise and range between 51 to $54^{\circ} \mathrm{C}$. This indicates heating of the weak solution at the SHX before entry to the generator. Results from figure 9 indicate that the SHX was able to perform its dual function of pre - cooling the strong solution before entry to the absorber as well as pre - heating the weak solution before entry to the generator. There was no 
sign of crystallization observed throughout the experiment. This is evident as seen from figure 9, the least recorded temperature of strong solution inlet to the absorber was $54^{\circ} \mathrm{C}$. Maintaining a strong solution concentration of $58 \%$, this falls well outside the crystallization zone as shown earlier in Figure 7.

Figure 10 shows the variation of system pressures with time. As seen in the figure, the chiller high pressure side (generator and condenser pressures) ranged between 7.3 and $8.5 \mathrm{kPa}$. The chiller low pressure side (evaporator and absorber) is seen to be more stable, staying almost constant at $1.1 \mathrm{kPa}$ throughout the experiment. Both high pressure side and low pressure side were well below atmospheric pressure throughout the experiment, an indication that vacuum state was maintained in the chiller throughout the experiment.

Figure 11 shows the chiller performance curves in terms of the generator heat load from the hot water stream, heat rejected to the cooling water stream at the absorber and condenser, as well as the cooling power from the chilled water at the evaporator. At the start of the experiment, 9:00 hr, the heat input to the generator can be seen to be very high at $7.3 \mathrm{~kW}$. This is because system inertia needs to be overcome at the start of the process before steady state is achieved. The heat rejected to the cooling water stream is seen to increase from $0 \mathrm{~kW}$ at 9:00 hr to $6.7 \mathrm{~kW}$ at 9:15 hr. This is as a result of the heat released in the condensation process. Steady state was achieved at about 9:30 hr. During steady state, the generator heat load ranged from 3.9 to $4.8 \mathrm{~kW}$, while the heat rejected to the cooling water stream ranged from 4.46 to $5.2 \mathrm{~kW}$. As mentioned earlier, the chilled water pump was set to start at 9:15 hr, 15 minutes after the hot water and cooling water pumps were on. Cooling power at the evaporator of $0.63 \mathrm{~kW}$ was recorded at 9:30 hr. This represents 15 minutes response time for cooling by the chiller. The chiller cooling power increases afterwards and stays fairly stable, ranging between 1.8 and $2.01 \mathrm{~kW}$. Maximum cooling power of $2.01 \mathrm{~kW}$ was recorded which represents $67 \%$ of nominal cooling capacity.

Figure 12 shows the variation of chiller COP with time. COP of 0.09 was recorded at 9:30 hr, this was the point when chilling at the evaporator commenced. The COP increased gradually from then up to 0.47 at $10: 15$ $\mathrm{hr}$. This was because the system inertia was overcome, leading to lower generator heat load and improved evaporator chilling power.

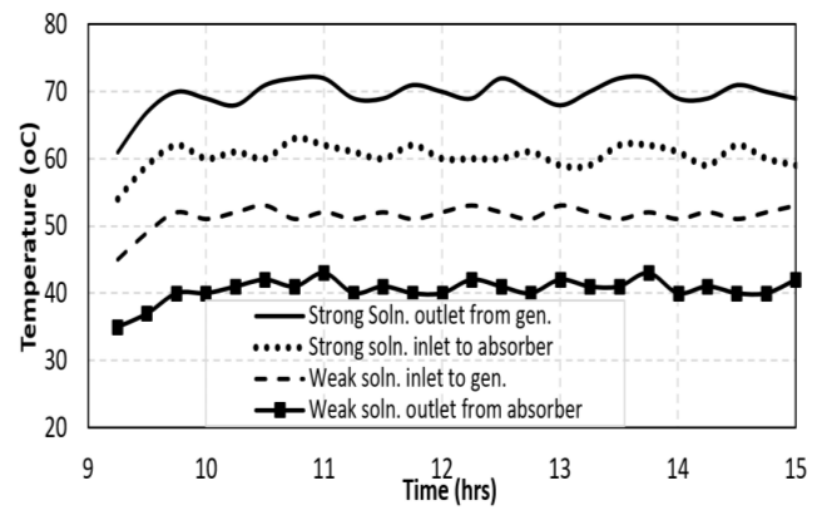

Figure 9: Variation of strong solution and weak solution temperatures with time

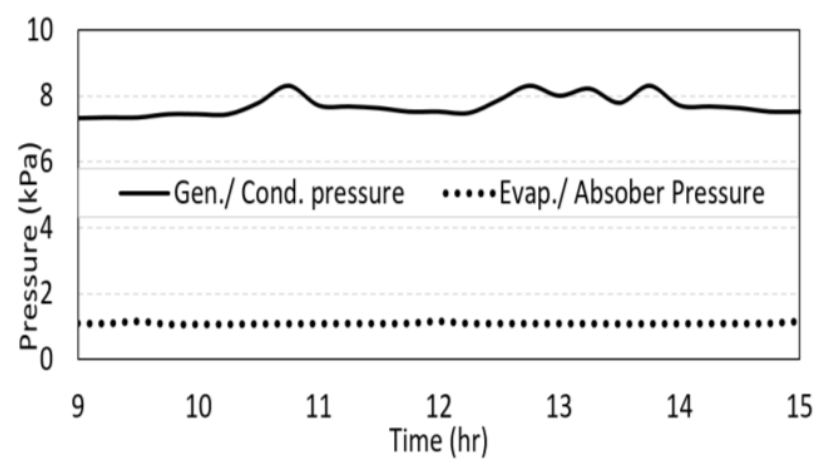

Figure 10: Variation of chiller pressures with time

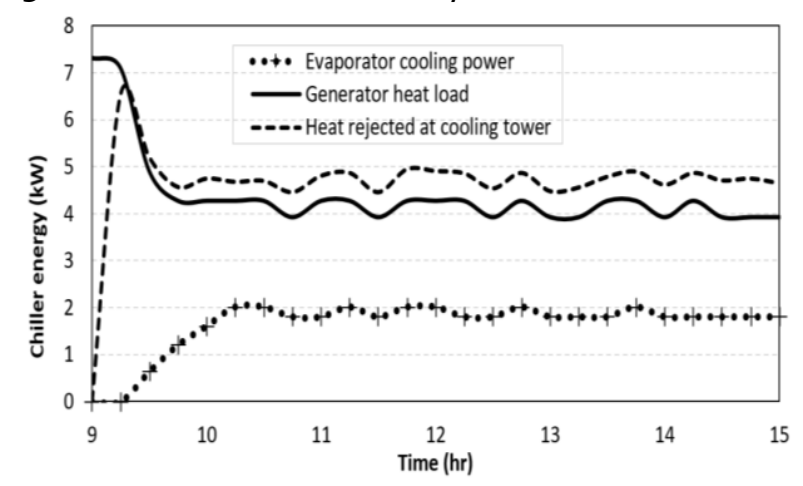

Figure 11: Variation of chiller power with time

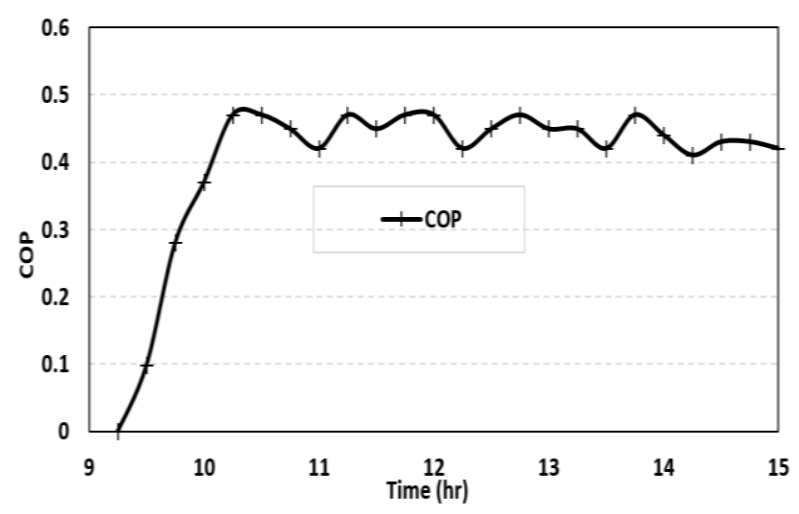

Figure 12: Variation of chiller COP with time

Once steady state was attained, the chiller COP is seen to stay above 0.4 till the close of the experiment. 
Maximum COP of 0.47 was recorded with a heat load at the generator of $4.27 \mathrm{~kW}$, evaporator cooling power of $2.01 \mathrm{~kW}$ and heat rejected to the cooling water stream of $4.68 \mathrm{~kW}$. Average COP recorded was 0.43 . This compares favourably with average COP reported in previous works of similar chiller capacities: a COP of 0.44 for a $5 \mathrm{~kW}$ capacity was reported by [9], a COP of 0.58 for an $8 \mathrm{~kW}$ capacity was reported by [13], while a COP of 0.358 for a $5 \mathrm{~kW}$ capacity was reported by [6]. This is an indication that the double tube configuration employed in the absorber performed satisfactorily.

\section{CONCLUSION}

An absorption chiller prototype of $3 \mathrm{~kW}$ capacity has been developed and experimentally evaluated. A double tube configuration was employed at the absorber to enhance tube wettability. The chiller operated satisfactorily without any sign of crystallization, while it was also able to maintain vacuum state throughout the experiment. Results showed that minimum chilled water outlet temperature of $16.3^{\circ} \mathrm{C}$ was achieved. Maximum cooling power of $2.01 \mathrm{~kW}$ was recorded, while maximum and average COP of 0.47 and 0.43 respectively were recorded.

\section{ACKNOWLEDGEMENT}

The author wishes to express sincere appreciation to Mr. Sunday Anthony of Safari Air Conditioning and Refrigeration, Kaduna, for a good job in fabricating the absorption chiller parts.

\section{REFERENCES}

[1] Choudhury, B., Saha, B. B., Chatterjee, P. K. and Sarka, J. P. "An overview of developments i 12 adsorption refrigeration systems towards a sustainable way of cooling", Applied Energy, Vol. 104, 2013, pp $554-67$.

[2] Kalkan, N., Young, E. A. and Celiktas, A. "Solar thermal air conditioning technology reducing the foot print of solar thermal air conditioning", Renewable and sustainable energy reviews, Vol. 16,2012 , pp $6352-6383$.
[3] Sarbu, I. and Sebarchievici, C. "General review of solar powered close sorption refrigeration systems", Energy conversion and management, Vol. 105, 2015, pp $403-442$.

[4] Chijioke, N. S. "Use of energy method to simulate the performance of $\mathrm{LiBr} / \mathrm{H}_{2} \mathrm{O}$ absorption system", Nigerian journal of technology, Vol. 29 Number 1, 2010, pp $77-85$.

[5] Henning, H. "Solar assisted air - conditioning of buildings, an overview", Applied thermal engineering Vol. 27, 2007, pp $1734-1749$.

[6] Franchini, G., Notarbartolo, E., Padovan, L., and Perdichizzi, A. "Modelling, design and construction of a micro scale absorption chiller", Energy Procedia Vol. 82, 2015 pp 577 - 583.

[7] Du, S., Wang, R. Z., Lin, P., Xu, Z. Z., Pan, Q. W. and $\mathrm{Xu}, \mathrm{S}$. C. "Experimental studies on an air cooled two stage $\mathrm{NH}_{3}-\mathrm{H}_{2} \mathrm{O}$ solar air conditioning prototype", Energy Vol. 45, 2012, pp 581 - 587.

[8] Ibarra - Bahena, J., and Romero, R. J. "Performance of different experimental absorber designs in absorption heat pump cycle technologies: A review". Energies, Vol. 7, 2014, pp $751-766$.

[9] Bolocan, S., Chiriac, F., Serban, A. and Dragomir, G. "Development of a small capacity solar cooling absorption plant", Energy Procedia, Vol. 74, 2015, pp 624-632.

[10] Prasartkaew, B. "Performance test of a small size lithium bromide - water absorption chiller", Energy Procedia, Vol. 56, 2014, pp 487 - 497.

[11] Izquierdo, M., Marcos, J. D., Palacios, M. E. and Gonzalez - Gil, A. "Experimental evaluation of a low power direct air cooled double effect $\mathrm{LiBr}-$ $\mathrm{H}_{2} \mathrm{O}$ absorption prototype", Energy, Vol. 37, 2012, pp $737-748$.

2] Wang, S. K. (2001). Hand book of air conditioning and refrigeration. Second edition. McGraw-Hill publishers, New York, U.S.A.

[13] Agyenim, F., Knight, I. and Rhodes, M. "Design and experimental testing of the performance of an outdoor Lithium Bromide - water solar thermal absorption cooling system with a cold store", Solar Energy, Vol. 84, 2010, pp 735 - 744. 